\title{
"We're Not Taken Seriously": Describing the Experiences of Perceived Discrimination in Medical Settings for Black Women
}

\author{
Ariel Washington $^{1}$ (1) J Jill Randall ${ }^{2}$
}

Received: 3 December 2021 / Revised: 24 February 2022 / Accepted: 25 February 2022 / Published online: 3 March 2022

○ W. Montague Cobb-NMA Health Institute 2022

\begin{abstract}
Objectives Cervical cancer disparities persist for Black women despite targeted efforts. Reasons for this vary; one potential factor affecting screening and prevention is perceived discrimination in medical settings. The purpose of this study was to describe experiences of perceived discrimination in medical settings for Black women and to explore the impact on cervical cancer screening and prevention.

Methods This paper presents mixed methods results using the Discrimination in Medical Settings (DMS) scale and qualitative interviews to understand the medical experiences of Black women. We administered the DMS scale to 48 Black women and interviewed five about their experiences engaging in the healthcare system.

Results High levels of perceived discrimination were experienced by our sample, with the majority of women having experienced discrimination in the medical setting. Qualitative data contextualized these results, including the impact on the patient-provider relationship and on the development of medical mistrust. Most women reported they had been screened within the last 3 years (75\%) and had seen a doctor within the past year (89.6\%).

Conclusions Black women are engaging in healthcare while experiencing perceived discrimination in medical settings. Future interventions should address the poor quality of medical encounters that Black women experience.
\end{abstract}

Keywords Perceived discrimination · Black women · African-American women $\cdot$ Cervical cancer $\cdot$ Screening and prevention

\section{Background}

Racial health disparities are evident in cervical cancer due to the high incidence and mortality rates of Black women compared with their White counterparts [1]. Black women have the second highest incidence rate and the highest mortality rate for cervical cancer and are often diagnosed at later stages [2]. Recent research has demonstrated that the BlackWhite difference in mortality is even more extensive than previously thought when correcting for hysterectomies [3]. The 5-year survival rate for Black women is $56 \%$ which is $10 \%$ lower than the national average for all stages [2].

Ariel Washington

amwash@umich.edu

1 School of Nursing, University of Michigan, Ann Arbor, MI, USA

2 Minneapolis, MN, USA
Cervical cancer screening is essential for early detection and treatment. White women are twice as likely to be screened for cervical cancer than Black women [4]. Thus, one intervention strategy to reduce adverse health outcomes in this population is to improve consistent cervical cancer screening practices. To accomplish this, researchers have spent considerable time understanding the barriers and facilitators of cervical cancer screening in Black women. Lack of awareness and knowledge of cervical cancer has been identified as barrier to screening practices for Black women [5-7]. The patient-provider relationship and strong recommendations have been identified as facilitators for cervical cancer screening uptake [6]. Unfortunately for Black women, the patient-provider relationship can be less than optimal due to perceived discrimination.

Perceived discrimination is defined as a behavioral manifestation of a negative attitude, judgment, or unfair treatment toward members of a group [8,9]. For Black women, perceived discrimination is a chronic stressor that negatively impacts their physical and mental health and their quality of 
life [10]. Black Americans have reported experiencing discrimination in medical settings [11-14]. Discrimination in medical settings can be harmful. It can damage the patientprovider relationship via miscommunication and perceived lack of respect [13] and negatively affect the quality of the healthcare experience [15]. Provider-based discrimination has been shown to lead to higher unmet needs, dissatisfactory healthcare interactions, and delay in seeking care [15].

Investigations into the role of perceived discrimination in the use of preventative services have had mixed results [14, 16]. Some studies have found that it did not directly impact cancer screening, while others have found that it impacted willingness to be screened [17]. Besides facing racial discrimination, Black women may also experience gender discrimination. Perceived gender discrimination has been found to negatively impact the receipt of pap smear screening [18].

Previous studies on the impact of discrimination on health behaviors have used the Experiences of Discrimination scale, Everyday Discrimination scale, Perceived Racism Scale, Racism and Life Experiences scale, or Schedule of Racist Events [10, 19]. These scales measure everyday discrimination but not discrimination specifically in medical settings. To the authors' knowledge, only a handful of studies have examined the impact of discrimination specifically in medical settings [11,20-22]. These studies used the Discrimination in Medical Settings (DMS) scale, which measures healthcare provider-based discrimination that has been validated for use in Black Americans [20].

This study uses the DMS to examine the relationship between perceived discrimination in medical settings and cervical cancer screening practices of Black women. There are two aims: (1) describe perceived discrimination experienced by Black women in medical settings; (2) explore the relationship between perceived discrimination, health behaviors, and cervical cancer screening habits.

Ethical approval was obtained by the University of Louisville institutional review board. Informed consent was obtained from all individuals participating in the study.

\section{Methods}

This study used a mixed-method approach with quantitative survey data and qualitative interviews to describe the experience of discrimination in medical settings for Black women. Data were collected from March to May 2020 as part of a pilot mobile health (mHealth) cervical cancer intervention study. Women who self-identified as African-American or Black, were at least 18 years old, and had not been diagnosed with cervical cancer were recruited. Recruitment efforts used flyers and social media posts and were aided by a community advisory board and social networks. Community advisory board members were eight African-American women from various professions who had participated in earlier work dedicated to developing cervical cancer and HPV educational messages. The use of social networks and social media allowed the reach of the study to expand to multiple states.

\section{Quantitative Approach}

\section{Data Collection}

Perceived discrimination was measured using the Discrimination in Medical Settings scale (DMS). The DMS is an adapted version of the Everyday Discrimination Scale that asks participants questions about their healthcare experience [20, 23]. Participants are asked whether they have experienced a specific scenario and how often have they experienced it. The prompt "Please indicate whether the listed events have happened to you" is followed by six scenarios, i.e., "You are treated with less courtesy than other people" and "You feel like a doctor or nurse is not listening to what you were saying." Responses range from 1 (never) to 5 (almost always). Perceived Discrimination scores were calculated by summing the responses, with higher scores indicating having experienced discrimination more frequently; total scores range from 6 to 30. The DMS was administered online through Qualtrics.

\section{Data Analysis}

Descriptive statistics were used to report on the demographic characteristics of the women in the sample. Perceived discrimination scores were calculated, and then descriptive statistics were reported to indicate how many participants have experienced the type of discrimination and how frequently they experienced it. Results are presented in Table 2. Bivariate analyses were used to examine group-based differences on perceived discrimination scores. All statistics were done using SPSS 27 with an alpha set at $p<0.05$.

\section{Qualitative Approach}

\section{Data Collection}

Qualitative data were collected after the quantitative data. A subset of women who had participated in a cervical cancer mHealth pilot study was invited to be interviewed about their medical encounters to gain a deeper understanding of discrimination in medical settings. Women were invited through phone and email to participate in virtual interviews using Microsoft Teams. Interviews were conducted using a semi-structured interview guide that asked the women about their medical experiences. The semi-structured interview guide was developed by one of the investigators based on 
previous work. Questions from the interview guide that are provided in supplementary material are from a section of the interview guide that was used for a pilot mHealth cervical cancer intervention study. Preliminary DMS data were discussed with the participants to facilitate a richer discussion about discrimination in medical settings. Interviews were conducted by one of the authors who have experience in qualitative interviewing (AW \& JR). The interviews lasted approximately $60 \mathrm{~min}$ and were recorded and transcribed verbatim. Five women participated in the qualitative interviews, detailing their personal experiences navigating the healthcare system and emergently mentioning the experiences of their friends and family when interacting with the health system.

\section{Data Analysis}

Using Dedoose, interviews were organized and coded by the co-authors. Codes were developed after being immersed in the data through repeated close reading and line-by-line coding. Qualitative analysis was guided by deductive content analysis [24]. Using the advice of Mayring [25], a categorization matrix and coding scheme were developed and data were coded toward those categories [26, 27]. Additionally, major themes were derived from transcripts and the DMS data. This resulted in a mix of predetermined codes and themes related to previous work, healthcare utilization models [28], and principles of critical race theory related to health [29]. Because the matrix was unconstrained, additional categories were allowed to emerge organically. An interrater reliability test using Cohen's kappa statistic was performed to assess the level of agreement between the two coders. A kappa score of 0.89 demonstrated excellent agreement $[30,31]$.

\section{Trustworthiness}

In addition to assessing inter-rater reliability, several other techniques suggested by Lincoln and Guba [32] were used to establish trustworthiness and rigor. After each interview, the researcher used memoing to track notes, tone indicators, and anything that stood out from the participant to better capture the overall tone and feel of the interview. The researchers, one who was more familiar with the subject matter and another who was not as familiar, often debriefed over the data analysis and discussed any possible alternative interpretations. Finally, negative case analysis was used to search for any instances in which a participant's perspective could be seen as differing from the majority. One individual did not recount any recent personal experiences of perceived discrimination in medical settings but did discuss her friends' and family members' experiences as well as her concern with experiencing it in the future.

\section{Results}

Sample characteristics are presented in Table 1. Fortyeight women participated in the DMS survey, and five women were interviewed for the qualitative portion of the study. All participants self-identified as African-American or Black. Over half $(56 \%)$ of the participants had never been married, and around a quarter $(27 \%)$ were currently married. The majority of the women indicated having an undergraduate or graduate degree, with only $8 \%$ having a high school diploma or less. Most participants (87.5\%) were currently employed, $39.6 \%$ had an income level between $\$ 40,000$ and $\$ 79,999$, and $37.5 \%$ made less than $\$ 40,000$. All participants reported having insurance, with $81.3 \%$ having private insurance and $18.8 \%$ having public (Medicaid/Medicare) insurance. Regarding cancer screening habits, $12.5 \%$ reported they had never been screened, and $75 \%$ reported that they had been screened within the last 3 years.

Descriptive statistics of the DMS scores (Table 2) illustrate how often the women have experienced discrimination in the medical setting. "Most of the time" was the most frequent response for 5 out of 6 types of discrimination, with "sometimes" being most frequently chosen for

Table 1 Demographic and socioeconomic characteristics of sample $(n=48)$

\begin{tabular}{|c|c|c|}
\hline Characteristic & $n$ & $\%$ \\
\hline \multicolumn{3}{|l|}{ Education } \\
\hline$<$ College & 8 & 16.7 \\
\hline College & 21 & 43.8 \\
\hline Graduate school or professional degree & 19 & 39.6 \\
\hline \multicolumn{3}{|l|}{ Employment } \\
\hline Working & 42 & 87.5 \\
\hline Not working & 6 & 12.5 \\
\hline \multicolumn{3}{|l|}{ Income } \\
\hline Less than $\$ 40,000$ & 18 & 37.5 \\
\hline$\$ 40,000$ to $\$ 79,999$ & 19 & 39.6 \\
\hline$\$ 80,000$ and above & 11 & 22.9 \\
\hline \multicolumn{3}{|l|}{ Marital status } \\
\hline Married & 13 & 27.1 \\
\hline Divorced/separated/widowed & 8 & 16.7 \\
\hline Never married & 27 & 56.3 \\
\hline \multicolumn{3}{|l|}{ Last doctor visit } \\
\hline Within the year & 43 & 89.6 \\
\hline Longer than a year & 5 & 10.4 \\
\hline \multicolumn{3}{|l|}{ Pap smear screening } \\
\hline Never & 6 & 12.5 \\
\hline Within 3 years & 36 & 75 \\
\hline Longer than 3 years & 6 & 12.5 \\
\hline
\end{tabular}


Table 2 Perceived discrimination in the medical settings

\begin{tabular}{llllll}
\hline Scenario & Never & Rarely & Sometimes & Most of the time & Always \\
\hline Treated with less courtesy & $1(2 \%)$ & $2(4 \%)$ & $15(31 \%)$ & $23(48 \%)$ & $7(15 \%)$ \\
Less respect than others & $0(0 \%)$ & $1(2 \%)$ & $16(33 \%)$ & $20(42 \%)$ & $11(23 \%)$ \\
Poorer service & $1(2 \%)$ & $2(4 \%)$ & $12(26 \% 0$ & $23(49 \%)$ & $9(19 \%)$ \\
Doctor or nurse acts as if you are not smart & $2(4 \%)$ & $4(8 \%)$ & $9(19 \%)$ & $17(35 \%)$ & $16(33 \%)$ \\
Doctor or nurse acts if they are better & $1(2 \%)$ & $6(13 \%)$ & $7(15 \%)$ & $20(42 \%)$ & $14(29 \%)$ \\
Not being listened to & $0(0 \%)$ & $4(8 \%)$ & $18(38 \%)$ & $16(33 \%)$ & $10(21 \%)$ \\
\hline
\end{tabular}

"not being listened to." The average score on the DMS was $22.6(\mathrm{SD}=4.8)$.

\section{Quantitative Findings}

There were no significant differences in DMS scores based on level of education, employment status, income, or marital status. Similarly, there were no significant differences in DMS scores based on health behaviors, such as last medical visit or having been recently screened.

\section{Integrating Qualitative and Quantitative Data}

The qualitative data exemplify discrimination in medical settings as measured by the DMS. Table 3 illustrates the connection between the DMS item responses and interview quotes. For example, the majority of the women have felt as if they were treated with less respect than others at least once in their medical encounters. One participant summarized this by saying that African-American women just "aren't taken seriously." In addition to personal experiences of discrimination in medical settings, participants shared examples of family members' and friends' experiences of discrimination. The survey data showed that $94 \%$ of the participants felt as if they were receiving poorer service during medical visits. The story a participant relayed of her friend's traumatic birth illustrates this particular manifestation of discrimination.

\section{Qualitative Findings}

We found that perceived discrimination impacted the participants' health behaviors and attitudes toward the healthcare system. Participants discussed how they, their family and friends, and their community have been impacted by discrimination in medical settings. The impact of both the personal and the collective resulted in three major themes: vigilant coping styles, collective experience and narrative, and medical mistrust. These themes feed into each other in

Table 3 Joint display of discrimination in medical settings scenarios with exemplar quotes

\begin{tabular}{|c|c|}
\hline Scenario & Exemplar quote \\
\hline Treated with less courtesy $(94 \%)$ & $\begin{array}{l}\text { Older Black women don't, tend not to trust. Health officials so much because of things that } \\
\text { happened in their past or the way they were treated. (Participant \#2) }\end{array}$ \\
\hline Less respect than others $(98 \%)$ & $\begin{array}{l}\text { African-American women we're so marginalized we are not listened to, we're not taken seri- } \\
\text { ously. (Participant \#2) }\end{array}$ \\
\hline Poorer service $(94 \%)$ & $\begin{array}{l}\text { One of my friends, like she was gonna be having a baby. She had a baby and she was in so } \\
\text { much pain. And then she was telling the doctor and I think that she was in so much pain } \\
\text { but they['re] just like Oh you'll be fine...It's very soon but she was like screaming that she } \\
\text { was like traumatized from that experience. (Participant \#3) }\end{array}$ \\
\hline Doctor or nurse acts as if you are not smart ( $88 \%)$ & $\begin{array}{l}\text { She said she doesn't know what the doctor told the nurses there, but like once they came } \\
\text { back the nurses came back in. They started treating her nice, nicer and very like very oh } \\
\text { sweet are being sweet to her. But they weren't doing that to her before. She told them she } \\
\text { was in school for clinical psychology. (Participant \#3) }\end{array}$ \\
\hline Doctor or nurse acts if they are better $(85 \%)$ & $\begin{array}{l}\text { Talking to people that [doctors and nurses] think are younger they like dumb things down } \\
\text { to the point that I don't think they're giving enough information about what it is that I'm } \\
\text { there for. 'You take this medicine you'll get better,' with no explanation of why they're } \\
\text { giving me that medicine or how it's going to get any better. (Participant \#1) }\end{array}$ \\
\hline Not being listened to $(92 \%)$ & $\begin{array}{l}\text { So in the whole process I was really discouraged that she wasn't taken seriously and that } \\
\text { there that she was it felt like she was really her own advocate and there were very simple } \\
\text { fixes that would approach. We actually called a hotline one time and I vividly remember } \\
\text { about her symptoms and they said, 'You know? This should only be used for emergency } \\
\text { life threatening situations only.' And that like haunts me because when we found out what } \\
\text { it was...(Participant \#5) }\end{array}$ \\
\hline
\end{tabular}


feedback loop of perceived discrimination. Collective narratives and experiences were formed as participants and their community became mistrustful of medical professionals due to experiences of past discrimination. This collective narrative resulted in participants adopting vigilant coping styles to protect against the potential impact of discrimination.

\section{Medical Mistrust}

In this study, medical mistrust was defined as the tendency to distrust medical systems and personnel, and to believe that they may not act in the best interest of the patient [33, 34]. We focused on beliefs and attitudes and also on health behavior that stemmed from medical mistrust. For the participants in this study, the impact of previous health encounters made it difficult to trust that healthcare professionals would have their best interest in mind. This led to participants contemplating how potential discrimination would impact their medical encounters with healthcare providers. As one participant noted, the difficulty in getting her sister diagnosed with cervical cancer impacted her ability to trust that a healthcare professional or organization would have in best interest in mind. This in turn made it difficult for her to engage in healthcare.

It took me a long time to trust that a doctor would really be able to hear me out because I feel like cancer that is as severe as it gets. (Participant \#5)

There is a myriad of ways in which medical mistrust impacts the healthcare experience of the community. Examples of these, as noted by one participant, are reducing the number of visits, being hesitant to trust medical advice, and turning to community members for medical advice.

I know a lot of the women in our lives don't do any of their like recommended health screenings, and I don't know if because, I've read a lot and heard from like my elderly Black females in my life, that they don't trust doctors a whole lot so I guess if they don't frequently go to the doctor's office and when they do the doctor tell them things and they don't know if it's true and they're off doing their own home remedy and regiments. (Participant \#1)

Participants' discussions of mistrust often intertwined with conversations about the role that racial identity plays in trust. According to some of the women, they and their family members are more likely to trust those they view as being part of the same racial/ethnic group. This is exemplified in the quote below.

For sure, I think that if you are terrified that your provider and the person that you're supposed to trust is providing you with information that you [think] is gonna hurt you or is inaccurate, if you're doing it yourself [gathering information] from someone that you do trust like your mother or your grandmother and it's information that was given to you from them, then I think that you feel safer. Like you feel like these people are making no efforts to hurt me and I know that like if my mother thinks that I should gargle peroxide in order to fight the coronavirus then it is probably safe for me to do. But if my doctor would suggest that I may have questions and concerns. (Participant \#1)

\section{Collective Experience and Narrative}

An emergent theme was the influence of the collective experience and building of a group narrative around discrimination in medical settings. The women discussed building a group narrative among their friends and family members and described how this narrative has influenced how they navigate the healthcare system. One example of this, highlighted in the following quote, is practicing vigilant advocacy when interacting with health professionals.

A couple of times, I'm 62, so once you get a certain age you don't take anything for granted. So once you get your voice and you learn to speak up for yourself, it might have happened once or twice, but not as long as I have a voice it will never happen to me again. Because I have been conditioned to speak and act. But [if] they're not listen[ing], get up and leave. If you can. (Participant \#2)

An important aspect of this theme that emerges is the influence of others' healthcare experiences on individuals' health behaviors and attitudes. For some participants, the collective experience of perceived discrimination has affected the attitudes and behaviors of their family members, as seen in the below quote.

[My mom] She does not trust modern medicine at all, and I think that has kind of trickled down to my two younger sisters who are kinda modeling really after her not trusting doctors. Not understanding, you know. If we take, if we do these things, why are we still dying? Why are Black women still you know losing babies? (Participant \#5)

\section{Vigilant Coping Styles}

The collective experience of perceived discrimination often led participants to adopt vigilant coping styles. Several participants discussed the need to be vigilant by overly preparing for the health visit or by becoming strong advocates for themselves. 
I'm not had...Negative experience with going to the doctor, but I think it also brought down the fact that when I go to the doctor's office I kinda want introduce myself and let them know that I'm a public health major and I understand healthcare system...I have yet to have a negative experience because I go real prepared. I have my questions ready. I'm asking all my questions and making sure that whatever time I spend there is sufficient enough. Sufficient really. (Participant \#3)

The DMS data show that participants reported optimal health practices: having recently seen a healthcare provider and being within guidelines for cervical cancer screening. The qualitative data add rich description to this engagement in healthcare.

Worrying about and anticipating discrimination in medical settings impacted the way the women and their friends and family navigated the healthcare system. In one instance, a participant described the harrowing experience of trying to get her sister diagnosed with cervical cancer. She mentioned that because of the journey she found it difficult to attend primary care visits. The participant detailed several instances in which she felt as if the doctor, nurses, and consultants were not listening to or acknowledging her sister's medical symptoms. This sentiment was also found in the DMS data, with over half of the participants reporting they were not listened to by their provider or nurse.

I will say that after my sister was diagnosed it was about a two-year span that I did not go to a primary care physicians I was still getting Pap smears and I was dropping into endocrinologist for a different like issue with PCOS. My sister wasn't diagnosed until March of 2016, and we have been going to doctors, emergency room, for very like serious symptoms beginning back in like August; and she was often prescribed with ibuprofen for pain, or she would be given laxatives for constipation. Recommend to go to see a what is that um. I can't think of the real name of it, but the back doctor [chiropractor]. (Participant \#5)

\section{Discussion}

The purpose of this study was to describe the experience of Black women in medical settings and the relationship between perceived discrimination and health behaviors. The results help deepen the picture of the healthcare experience for Black women. Black women were found to have experienced high levels of perceived discrimination in all six DMS scenarios. The qualitative results promoted a richer understanding of this by illuminating how participants' various experiences of perceived discrimination have impacted how they navigate the healthcare system. Along with high levels of discrimination, high levels of engagement in care were reported, with many participants having seen the doctor recently and having been screened for cervical cancer.

Our findings are consistent with other studies that have used the DMS scale to measure perceived discrimination $[11,22]$. There were only a few women in our sample who could be classified as experiencing low levels of perceived discrimination; the vast majority frequently experienced discrimination. This differs from a few studies that used the same scale and found low levels of discrimination in the medical setting.

The literature has linked perceived discrimination with socioeconomic factors such as education [35] and income [14]. In this study, there were no significant differences in perceived discrimination based on education and income. Women in this sample were highly educated, with over half of the respondents having a college degree or more. Clearly, their educational status did not protect them from experiencing discrimination in their medical encounters. Higher household income levels also did not protect them. Discrimination scores were high across all groups, which is concerning given the negative impact of discrimination on health.

One surprising finding of our study was that although the women reported experiencing high levels of discrimination, they still reported optimal health behavior. This would seem counterintuitive, as the literature notes perceived discrimination can negatively impact healthcare utilization. However, these findings reinforce Jacobs et al. [18], whose study demonstrated similar results regarding cervical cancer screening. A possible interpretation of this contradiction is that the women actively engage in healthcare despite having negative experiences with it.

A strength of this study is the qualitative interviews, which give poignant examples of what discrimination looks like in this context. As Graham et al. [29] noted, the vital perspectives of marginalized individuals need to be investigated in population health sciences. In this study, the women experienced perceived discrimination personally and also had stories of their friends and family experiencing it. The latter was an emergent discussion that the women often brought up unprompted when discussing their own personal experiences.

The qualitative data aligns with Gary et al. [36] in demonstrating that perceived discrimination impacts how Black women navigate the healthcare system. As one participant noted, she took active measures to protect herself during medical encounters by researching her medical problems and explicitly mentioning to her healthcare team that she has a degree and experience. This is similar to how Himmelstein et al. [37] discuss perceived discrimination and its relationship with vigilant coping styles. In response to the potential for discrimination, individuals 
adopt a vigilant coping style, which then leads to an increase in stress and adverse health outcomes.

The qualitative data showed how participants connected their experiences of perceived discrimination with that of their family members and friends, turning what is often seen as a singular event into a collective experience. It was, as Graham et al. [29] notes, a shared, collected experience of race and racism passed among the women and their network, as stories and experiences were told to form community memory. For many of the women, their perception of healthcare visits was influenced by the perceptions of their friends and family members. While discussing their personal experiences in medical settings, they would organically start to discuss the experiences of their friends and family members with little prompting from the interviewer. For some, it was the negative experiences of the friends and family members that prompted a change in health behaviors, loss of trust in healthcare providers, or increased worry over personally experiencing discrimination. Their individual experience was interwoven and tightly connected to the experience of their family/friends.

\section{Limitations}

There are several limitations of this study. While all participants were over the age of 18 , age was not captured in the data. This is a limitation that would make it challenging to assess generational differences. The DMS does not ask for a specific timeframe for when perceived discrimination was experienced; it is possible that if the participants had been asked to recall the most recent experience or assess within the last 12 months, the level of perceived discrimination may have been different. Finally, health behavior data relied on self-report.

A strength, and possible limitation, of this study is the uniqueness of the sample and timeframe. These data were captured in April and May of 2020 when social protests brought heightened attention to racial injustice. It may be that the women were more aware of discrimination given the prevalence of protests around the nation and increased attention to racial injustice. However, such protests have been occurring, to a lesser degree, since 2016, and the conditions surrounding the protested issues have existed for decades in the USA. Given these circumstances, it would be difficult to determine how much historical context may have influenced reports of perceived discrimination. Studies that capture data during this time will have to consider how the burgeoning social awareness around discrimination may impact their data.

\section{Future Research}

There are two directions future research should explore: the intersection of discrimination that Black women face in medical settings and the quality of their healthcare encounters. In this study, perceived discrimination was experienced frequently by the majority of participants, yet most participants still engaged in optimal healthcare behaviors. Self-reported screening was high in this sample, although it is possible that the screening encounters may not have been positive experiences for the women. Just because the women were engaging in healthcare does not mean the experience was pleasant and not potentially detrimental to their quality of life. Future research should use qualitative and quantitative methods to explore the quality of medical encounters and the potential impact on cervical cancer screening. It would be especially important to hear from the participants directly why they continue to engage in care despite reports of discrimination in medical settings. Finally, due to having multiple group memberships, the women in this study have potentially experienced both race- and gender-based discrimination. Future research should explore the relationship between these and the implications for cervical cancer screening.

\section{Appendix}

Semi-structured interview guide for qualitative inquiry

- For those who have recently seen a physician or healthcare provider, tell me about your typical experience?

- For those who have not recently seen a physician or healthcare provider, tell me about why you may not have seen one?

- Why do you think women in your community may not have seen a physician recently?

- How do you feel your next doctor's appointment will go?

*Because this was a semi-structured interview some of the questions that produced the richest data came as informal conversations starters and clarifying questions with the participants.

Funding This work received research support from the National Cancer Institute institutional training grant T32-CA-236621. The content is solely the responsibility of the authors and does not necessarily represent the official views of the National Institutes of Health or the National Cancer Institute.

\section{Declarations}

Ethics Approval Approval was obtained from the institutional review board of University of Louisville. 
Consent to Participate Informed consent was obtained from all participants included in this study.

Competing Interests The authors declare no competing interests.

\section{References}

1. Yoo W, Kim S, Huh WK, Dilley S, Coughlin SS, Partridge EE, et al. Recent trends in racial and regional disparities in cervical cancer incidence and mortality in United States. PloS one. 2017;12(2):e0172548.

2. Siegel RL, Miller KD, Fuchs HE, Jemal A. Cancer Statistics, 2021. CA Cancer J Clin. 2021;71(1):7-33.

3. Beavis AL, Gravitt PE, Rositch AF. Hysterectomy-corrected cervical cancer mortality rates reveal a larger racial disparity in the United States. Cancer. 2017;123(6):1044-50. https://doi.org/10. 1002/cncr.30507.

4. Johnson NL, Head KJ, Scott SF, Zimet GD. Persistent disparities in cervical cancer screening uptake: knowledge and sociodemographic determinants of Papanicolaou and human papillomavirus testing among women in the United States. Public Health Rep (Washington, DC : 1974). 2020;135(4):483-91. https://doi.org/ $10.1177 / 0033354920925094$.

5. Akinlotan M, Bolin JN, Helduser J, Ojinnaka C, Lichorad A, McClellan D. Cervical cancer screening barriers and risk factor knowledge among uninsured women. J Community Health. 2017;42(4):770-8. https://doi.org/10.1007/s10900-017-0316-9.

6. Brown DR, Wilson RM, Boothe MAS, Harris CES. Cervical cancer screening among ethnically diverse black women: knowledge, attitudes, beliefs, and practices. J Natl Med Assoc. 2011;103(8):719-28. https://doi.org/10.1016/S0027-9684(15) 30411-9.

7. Strohl AE, Mendoza G, Ghant MS, Cameron KA, Simon MA, Schink JC, et al. Barriers to prevention: knowledge of HPV, cervical cancer, and HPV vaccinations among African American women. Am J Obstet Gynecol. 2015;212(1):65.e1-.e5. https:// doi.org/10.1016/j.ajog.2014.06.059.

8. Banks KH, Kohn-Wood LP, Spencer M. An examination of the African American experience of everyday discrimination and symptoms of psychological distress. Community Ment Health J. 2006;42(6):555-70. https://doi.org/10.1007/s10597-006-9052-9.

9. Williams D, Spencer M, Jackson J, Contrada R, Ashmore R. Self, social identity, and physical health: Interdisciplinary explorations. 1999.

10. Pascoe EA, Smart RL. Perceived discrimination and health: a meta-analytic review. Psychol Bull. 2009;135(4):531.

11. Benjamins MR, Middleton M. Perceived discrimination in medical settings and perceived quality of care: a population-based study in Chicago. PLoS ONE. 2019;14(4):e0215976. https://doi. org/10.1371/journal.pone.0215976.

12. Casagrande SS, Gary TL, LaVeist TA, Gaskin DJ, Cooper LA. Perceived discrimination and adherence to medical care in a racially integrated community. J Gen Intern Med. 2007;22(3):389-95.

13. Hausmann LR, Hannon MJ, Kresevic DM, Hanusa BH, Kwoh CK, Ibrahim SA. Impact of perceived discrimination in health care on patient-provider communication. Med Care. 2011;49(7):626.

14. Hausmann LR, Jeong K, Bost JE, Ibrahim SA. Perceived discrimination in health care and health status in a racially diverse sample. Med Care. 2008;46(9):905.
15. Lee C, Ayers SL, Kronenfeld JJ. The association between perceived provider discrimination, health care utilization, and health status in racial and ethnic minorities. Ethn Dis. 2009;19(3):330.

16. Trivedi AN, Ayanian JZ. Perceived discrimination and use of preventive health services. J Gen Intern Med. 2006;21(6):553-8.

17. Mouton CP, Carter-Nolan PL, Makambi KH, Taylor TR, Palmer JR, Rosenberg L, et al. Impact of perceived racial discrimination on health screening in Black women. J Health Care Poor Underserved. 2010;21(1):287-300. https://doi.org/10.1353/ hpu.0.0273.

18. Jacobs EA, Rathouz PJ, Karavolos K, Everson-Rose SA, Janssen I, Kravitz HM, et al. Perceived discrimination is associated with reduced breast and cervical cancer screening: the Study of Women's Health Across the Nation (SWAN). J Womens Health. 2014;23(2):138-45.

19. Paradies Y, Ben J, Denson N, Elias A, Priest N, Pieterse A, et al. Racism as a determinant of health: a systematic review and metaanalysis. PloS One. 2015;10(9):e0138511.

20. Peek ME, Nunez-Smith M, Drum M, Lewis TT. Adapting the everyday discrimination scale to medical settings: reliability and validity testing in a sample of African American patients. Ethn Dis. 2011;21(4):502-9.

21. Hall OT, Jordan A, Teater J, Dixon-Shambley K, McKiever ME, Baek M, et al. Experiences of racial discrimination in the medical setting and associations with medical mistrust and expectations of care among black patients seeking addiction treatment. J Subst Abuse Treatment. 2021;108551.

22. MacDonald S, Hausmann LR, Sileanu FE, Zhao X, Mor MK, Borrero S. Associations between perceived race-based discrimination and contraceptive use among women veterans in the ECUUN Study. Med Care. 2017;55(Suppl 9 2):S43.

23. Bird ST, Bogart LM. Perceived race-based and socioeconomic status (SES)-based discrimination in interactions with health care providers. Ethn Dis. 2001;11(3):554-63.

24. Drisko JW, Maschi T. Content analysis. Pocket Guides to Social Work R; 2015.

25. Mayring P. Qualitative content analysis: theoretical foundation, basic procedures and software solution. 2014.

26. Elo S, Kyngäs $\mathrm{H}$. The qualitative content analysis process. J Adv Nurs. 2008;62(1):107-15.

27. Assarroudi A, Heshmati Nabavi F, Armat MR, Ebadi A, Vaismoradi $M$. Directed qualitative content analysis: the description and elaboration of its underpinning methods and data analysis process. J Res Nurs. 2018;23(1):42-55.

28. Andersen RM. Revisiting the behavioral model and access to medical care: does it matter? J Health Soc Behav. 1995;36(1):1-10. https://doi.org/10.2307/2137284.

29. Graham L, Brown-Jeffy S, Aronson R, Stephens C. Critical race theory as theoretical framework and analysis tool for population health research. Crit Public Health. 2011;21(1):81-93.

30. Cohen J. Statistical power analysis for the behavioral sciences. 2nd ed. Hillsdale: L. Erlbaum Associates; 1988.

31. De Vries H, Elliott MN, Kanouse DE, Teleki SS. Using pooled kappa to summarize interrater agreement across many items. Field Methods. 2008;20(3):272-82.

32. Lincoln YS. Naturalistic inquiry / Yvonna S. Lincoln, Egon G. Guba. vol Accessed from https://nla.gov.au/nla.cat-vn2938416. Beverly Hills, Calif: Sage Publications; 1985.

33. Thompson HS, Valdimarsdottir HB, Winkel G, Jandorf L, Redd W. The Group-Based Medical Mistrust Scale: psychometric properties and association with breast cancer screening. Prev Med. 2004;38(2):209-18. https://doi.org/10.1016/j.ypmed.2003.09.041.

34. Williamson LD, Bigman CA. A systematic review of medical mistrust measures. Patient Educ Couns. 2018;101(10):1786-94. https://doi.org/10.1016/j.pec.2018.05.007. 
35. Brondolo E, Hausmann LR, Jhalani J, Pencille M, AtencioBacayon J, Kumar A, et al. Dimensions of perceived racism and self-reported health: examination of racial/ethnic differences and potential mediators. Ann Behav Med. 2011;42(1):14-28.

36. Gary F, Still C, Mickels P, Hassan M, Evans E. Muddling Through the Health System: Experiences of Three Groups of Black Women in Three Regions. J Natl Black Nurses Assoc. 2015;26(1):22-8.
37. Himmelstein DU, Thorne D, Warren E, Woolhandler S. Medical bankruptcy in the United States, 2007: results of a national study. Am J Med. 2009;122(8):741-6.

Publisher's Note Springer Nature remains neutral with regard to jurisdictional claims in published maps and institutional affiliations. 